\title{
Migraciones y desarrollos asimétricos en la frontera noreste: el caso de Reynosa, hasta 1930
}

\author{
Fernando Cámara Barbachano \\ Instituto Nacional de Antropología e Historia
}

\section{Resumen}

El presente artículo muestra la extensión y los efectos de distintos cohortes, flujos, corrientes y oleadas migratorias de esta parte del noreste de México. En su primera parte se muestra brevemente el perfil histórico estructural de esta región; es decir, las situaciones del proceso de colonización y condiciones del crecimiento económico y de su desarrollo social. Con el análisis de estos hechos, se presentarán los fundamentos sociológicos que han contribuido a la creación de un nuevo orden social en el noreste.

Palabras clave: migración interna, indígenas, desarrollo, asentamientos humanos.

\begin{abstract}
This article shows the extent and effects of diverse groups, flows, trends, and migratory waves of this region from the Northwest of Mexico. The first part briefly shows the historic structural profile of this region; it means, the facts existing around the process of colonization as well as the economical growth conditions, and the social development. Through the analysis of these facts, it will present the sociological fundaments that have contributed to create a new social order at Northeast.
\end{abstract}

Keywords: internal migration, Indian groups, development, human settlements. 


\title{
MIGRACIONES Y DESARROLLOS ASIMETRICOS EN LA FRONTERA NORESTE: EL CASO DE REYNOSA, HASTA 1930.
}

\author{
Por \\ Fernando Cámara Barbachano*
}

No hay duda de que los movimientos migratorios de población están asociados al crecimiento económico y al proceso de desarrollo social, cultural y político. En el presente ensayo intentamos mostrar la extensión y los efectos de los varios cohortes, flujos, corrientes y oleadas migratorias en una porción del noreste del país. Referencias particulares al municipio de Reynosa, Tamaulipas, cubrirán partes de la naturaleza y contenido de sus estructuras socioeconómicas, culturales y políticas. El contenido de este trabajo permitirá primero, conocer, aunque superficialmente, el perifl históricoestructural: situaciones del proceso de colonización y condiciones del crecimiento económico y del desarrollo social. Después, el análisis de esos hechos ofrecerán los fundamentos sociológicos que han contribuido a la creación de un nuevo orden social en el noreste.

A guisa de hipótesis sostenemos que esas situaciones y condiciones histórico-estructurales caracterizan un sistema de relaciones sociales asimétrico, pleno de contradicciones.

Cabe asentar que los datos y cifras que ofrecemos en seguida, representan nuevas contribuciones al estudio extenso que realizamos desde hace cinco años sobre migración, crecimiento económico y desarrollo social y cultural en la frontera de México con los Estados Unidos de América. ${ }^{1}$ Nuestros

\footnotetext{
* Fl autor es investigador del Instituto Nacional de Antropologia e Historia y catedrático de la Facultad de Ciencias Politicas y Social de la UNAM. El ensayo aqui presentado fue posible por la ayuda en financiamiento otorgada por el Consejo Nacional de (iencia y Tecnologia.

1 Hacemos referencia aquí a las siguientes obras del autor:

Mr. Mexican migrant workers; winners or losers? Paper presented to the XXXV Annual Meeting of the Society for Applied Anthropology. Amsterdam. 1975. MS. Panorámica Migratoria de México a los estados fronterizos de los Estados Unidos de Norteamérica. Ponencia leída en el Simposio Bilingüe sobre The Interelations between Mexico and United States Cultures on the Border. The University of Texas at El Paso. 1975. Movimientos y corrientes migratorias de México a los Estados Unidos. Ponencia presentada a la XIV Mesa Redonda de la Sociedad Mexicana de Antropología, celebrada en Tegucigalpa, Honduras. Tomo 2: 389-396. México, D.F. 1976. MS. Some anthropological Perspectives on the Mexico-United States Borderland. Paper read at the Symposium on Antropología Fronteriza/Borderland Anthropology, sponsored by The Cross Cultural Southwest Ethnic Study Center. The University of Texas at El Paso. 1976. MS. Investigación a realizar en los municipios de Mexicali y San Luis Rio Colorado. Ponencia discutida en la Mesa Redonda sobre Historia y Antropología realizada por la Delegación del INAH en el Noroeste, en Ensenada. 1976. Is Regional Development a positive strategy for México?: The border case. Paper read at the 37th Annual Meeting of The Society for Applied Anthropology. San Diego. 1977. MS. Differential migration streams in Mexican border cities. Paper read at the 76th Annual Meeting of the American Anthropological Association. Houston. 1977. MS. Migration and development in Northwest Mexico. Paper read at the 38th Arinual Meeting of The Society for Applied Anthropology. Mérica. 1978. MS. Socioeconomic change in Mexicali. Paper read at the 77 th Annual Meeting of the American Anthropological Association. Los Angeles. 1978. Differential migration streams, economic growth, and socio-cultural changes in Mexican border cities. En: Migration Across Frontiers: Mexico and the
} 
estudios, patrocinados por el Instituto Nacional de Antropología e Historia cuentan, además, con la ayuda de financiamiento por parte del Consejo $\mathrm{N}_{2}$ cional de Antropología e Historia, de la Escuela de Ciencias Políticas y Sociales de la UNAM y de la Escuela de Ciencias Químicas de la Universidad Autónoma de Tamaulipas.

La parte baja del Río Bravo fue área habitada por cerca de 30,000 nómadas, formando numerosas bandas de cazadores y de recolectores, de filiación lingüistica Karankawa, en los tiempos cuando los españoles comenzaron a explorar esa región. ${ }^{2}$

Por otro lado, el intento de evangelización por parte de la orden Franciscana nunca obtuvo resultados significativos. Las Villas españolas fundadas entre 1749 y 1756 , por José de Escandón sirvieron más como puestos militares defensivos, cada vez que extranjeros (colonos franceses e ingleses) trataban de invadir los lugares potencialmente importantes por su economía productiva.

Desde finales del siglo XVII, la presencia de los franceses en las costas atlánticas de América fue percibida como una situación amenazadora por parte del gobierno virreinal de la Nueva España. Sin embargo, varias décadas habrían de transcurrir antes que movimientos migratorios y de colonización fueran seriamente ejecutados.

José de Escandón, funcionario, militar y empresario español, residente para esa época en Querétaro, encabezó la primera, y bien organizada, expedición colonizadora al área norte del actual estado de Tamaulipas en 1748. Al mismo tiempo, otros grupos de soldados, colonos y misioneros abandonaban sitios ya poblados de Coahuila, el Nuevo Reino de León y San Luis Potosí para encontrarse con las partidas de Escandón. Entre 1749 y 1750, Camargo, Reynosa, Revilla (hoy Guerrero), Mier y Laredo (actual Texas) fueron fundadas como Villas, ${ }^{3}$ en las riberas del Río Bravo, mientras otras, como San Fernando, un tanto más hacia tierra adentro. ${ }^{4}$

United States: 101-126, Editado por Fernando Cámara y Roberto Van Kemper, State University of New York at Albany. 1979. Migration to the borderlands: Mexicali and Reynosa as ilustrative cases. Paper read at the Western Social Science Association. Lake Tahoe. 1979.

2 Weaver, Thomas, Fernando; Cámara, Theodore E. Downing \& Barton Clark (editors). MS. An annoted bibliography of Mexican migration. A binational research project funded jointly by Mexico's Consejo Nacional de Ciencia y Tecnología and the United State's National Science Foundation. Mexico City \& Tucson. 1976.

3 Cámara. Differntial migration..., pp. 103 y 116. La categoría política de villa corresponde a una condición de prestigio, es decir, una localidad con Ayuntamiento establecido, y no a una situación de importancia demográfica y/o económica.

4 Gurría, Jorge, 1961. El Nuevo Santander. En “Homenaje a Pablo Martínez del Río” en el XXV Aniversario de la edición de Los orígenes americanos. Instituto Nacional de Antropología e Historia. México, pp. 454-56. 
De hecho y por derecho, la Villa de Nuestra Señora de Guadalupe de Reynosa fue el nombre oficial dado al nuevo sitio o asentamiento humano el mismo día de su fundación, marzo 14 de 1749 . Fincada en una área desértica, unas quinientas varas más hacia el norte de su actual situación, sus tierras carecían de agua potable, aunque disponían de demasías cuando las inundaciones periódicas del Río Bravo. El maíz fue el cultivo principal, sin ser de ninguna manera abundante la producción, mientras miles de cabezas de ganado menor y cientos de caballos, burros y ganado vacuno pastaron en los montes que recién recibían a estos animales. Unas 50 familias fincaron sus chozas y sus bienes, a sabiendas que el terreno resultaba nada a propósito para cosechas. La escaséz de agua era la dificultad más seria que se oponía al desarrollo. No obtante, la ganadería, la explotación de minas de sal y el trabajo en pequeños talleres de curtiduría permitieron cierto crecimiento. Así, también comenzó a funcionar la congregación de indios, en la Misión de San Joaquín del Monte. Constaba esta congregación de 96 familias y un total aproximado de 300 personas de la nación, banda o tribu de los comecrudos, 8 familias de los nazas, 6 de los narices y 17 de los tejones, unos ocho años después, es decir, en 1757, según asienta fray Agustín Fragoso, ministro franciscano en la misión. La congrega se había reducido en casi una tercera parte, ya que al escasear el maíz, las frazadas, mercería y tabaco, que les daban, volvían a andar dispersos por los campos. ${ }^{5}$

La situación anterior determinó en mucho el fracaso de la vida misional. Los indios, a la llegada de los españoles, se remontaron a las serranías, y al ver o saber cómo se ocupaban sus tierras por gentes y ganados comenzaron a rebelarse en grandes y pequeños movimientos suvbersivos. Ello motivó enérgicas campañas militares para someterlos y exterminarlos. Se salvaron de morir aquellos nativos que buscaron o encontraron refugio en las escasas misiones o en las villas recién fundadas, donde iniciaron su proceso de aculturación. ${ }^{6}$

En lo personal, he estimado que hacia fines del siglo XVII la villa de Reynosa podría tener unos 700 residentes, entre españoles y mestizos, y unos 1,500 indios. Para todo el distrito norte de la entonces Provincia del Nuevo Santander, con las municipalidades de Laredo, Revilla, Mier, Camargo ₹ San Fernando, además de Reynosa, he estimado una población no mayor de 8,000 entre españoles y mestizos, y unos 12,000 indios diseminados en un área de 300 millas de largo por 100 de ancho, a quienes no se había controlado o matado.

\footnotetext{
De Lejarza, Fidel. La conquista espiritual del Nuevo Santander. Consejo Superior de Investigaciozes Científicas. Madrid. 1947, pp. 222-25.

6 Anónimo. Datos históricos sobre el estado de Tamaulipas y sus principales ciudades. S/p/i/; S/f.
} 
Por otro lado, la reorganización de las provincias internas y el establecimiento de las intendencias (cuerpo regional de autoridad y de desarrollo que incrementó los trabajos de infraestructura realizados en la Nueva España) pudo afectar mucho el área de Reynosa. Con cierta medida, los colonos y los jefes militares, como empresarios privados, seguramente tomaron posiciones dirigentes en su expansión territorial y en el desarrollo de su ganadería. Ello, habría de modificar más aún el uso de la tierra y la composición de la población.

Los habitantes indígenas disminuían ante el mayor contingente de inmigrantes criollos y mestizos, mientras la orientación monetaria de los colonizadores contribuía a la estructuración de un nuevo orden socio-económico en el noreste de México, incluyendo, desde luego, la municipalidad de Reynosa. Para 1810, estimamos, las cifras de población se habían trocado diferentes en ese distrito norte: 12,000 criollos y mestizos y unos 8,000 indígenas. ${ }^{7}$

Cabe asentar ahora que, como es bien sabido, a los soldados españoles y otros elementos militares de mayor categoría, y todos como conquistadores, se les dió tierra en pago o recompensa por sus hazañas y servicios a la Corona. Las extensiones variaban entre 20 y 100 hectáreas, por suertes de tierras y solares para casas; pero, a quienes solicitaban tierras para colonizar les eran concedidas extensiones mucho mayores. De hecho, carecemos de datos y cifras que pudieran ilustrar la situación que prevaleció en la Villa de Reynosa y, más tarde, en su municipalidad. No obstante, estimamos que las tierras repartidas entre las primeras familias fundadoras, aquellas que fueron con Escandón, pudieron constituir entre 50,000 y 100,000 hectáreas. Si en 1749 los vecinos fundadores residieron en un solo lugar, la Villa, es bien posible que en décadas posteriores algunos hubiesen erigido sus chozas y casas de habitación en o cerca de sus campos agrícolas y sitios ganaderos. Ello debió haber dado lugar a los primeros rạnchos, en su acepción de lugar despoblado donde se albergan varias personas (una o más familias).

Hacia fines del siglo XVIII, los pocos indios de la misión religiosa y aquellos que ya habían hecho su vida en o cerca de Villa de Reynosa tenían, seguramente, algunas opciones: trabajo colectivo en sus cultivos de maíz, peones en las heredades de los criollos y mestizos; jornaleros en la explotación de la sal y en los talleres de curtiduría, y el servicio doméstico. Ya entonces, suponemos los excedentes de producción ganadera principalmente, diferenciaba económica, política y socioculturalmente a los habitantes de la municipalidad, tal incipientes estratos o "clases". Mucho del éxito econó-

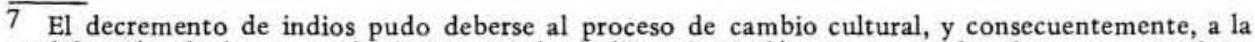
modificación de la categoría de identidad: de llamarlos indígenas a considerarlos como mestizos. 
mico y del cierto poder político que pudo haber existido entre algunos de los residentes dependỉan, fundamentalmente, de la mayor extensión de tierras que fueran capaces de controlar o de aprovechar en la ganadería extensiva.

$\mathrm{Y}$ es bien posible que derechos de propiedad territorial o, cuando menos de usufructo, hubiesen alcanzado sitios en las presentes áreas de McAllen, Edinburg, San Benito y Harlingen, en el actual estado de Texas. La memoria presentada a las Cortes españolas por don Miguel Ramos Arizpe, en 1811, contiene referencias sobre la cría de ovejas y cabras, en la parte norte, sobre el Río Grande, donde están fomentadas estas especies muy considerablemente. ${ }^{8}$ Por lo que toca a la municipalidad de Reynosa, estimamos en unos mil sus residentes criollos y mestizos y otros tantos indios, muy dispersos, entre 1810 y 1920 .

Durante las primeras décadas del siglo XIX, la escasa población y la falta de comunicaciones en el distrito norte del recién Estado de Tamaulipas, pero su abundante producción ganadera y el importante comercio, controlado por los acaparadores y las aduanas de Veracruz y de la ciudad de México, facilitaron la presencia de exploradores, filibusteros, comerciantes y potenciales colonos anglos. Advertencias sobre estos particulares, como factores muy negativos, ya habían sido expresadas por los visitadores Félix Calleja en $1795 \mathrm{y}$, posteriormente por fray Agustín de Morfi. ${ }^{9}$

Por otro lado, la expansión territorial y económica de los Estados Unidos de Norteamérica, junto a la tambaleante posición de nuestro país, tal nación independiente, propiciaron los programas de concesión y de colonización de tierras, patrocinados por el gobierno mexicano. No obstante, el aprovechamiento mayúsculo lo obtuvieron colonos anglos y no pocos terratenientes, ciudadanos mexicanos, de la región noreste para quienes el no permitir el asentamiento de colonos nacionales, pero sí comerciar con los vecinos del norte, importaba más que la integración política, el fortalecimiento económico y el desarrollo sociocultural del México independiente. Tal parece que la identidad empresarial y no nacionalista ya se dejaba ver.

Además, la miopía o la corrupción, o ambas, de los gobiernos centralistas y federalistas, ante las problemáticas situaciones y condiciones de la frontera noreste, permitieron constantes escaramuzas contra indios apaches y comanches así como contra filibusteros anglos, ocupantes de Texas y la

\footnotetext{
8 Ramos Arizpe, M. Memoria sobre el estado de las Provincias Internas de Oriente, presentada a las Cortes de Cádiz. Asociación de Bibliófilos Mexicanos. México. 1932.

9 Vizcaya Canales. "Factores adversos para el desarrollo de las Provincias Internas en los últimos años de la dominación española". En Estudios de Historia del Noroeste. Sociedad Nuevoleonesa. Monterrey. 1972, pp. $170-172$ y $175-176$.
} 
eventual "República del Río Bravo," como movimiento independentista que anhelaba la segregación territorial y política del Noreste. ${ }^{10}$

En esas décadas, otros sucesos significativos para nuestro tema merecen ser asentados. Así, por ejemplo, la antigüa Congregación de El Refugio, satélite de la municipalidad de Reynosa, fue segregada y convertida en localidad independiente y puerto de altura, en 1823, dando lugar a la Villa de Matamoros, actual ciudad del mismo nombre, que prosperó ampliamente por su comercio exterior. Otro evento fue el inicio del cultivo de algodón en el noreste, hacia los años cincuenta. Más ataques de indios y de aventureros texanos sucédense en las márgenes del bajo del Río Bravo, mismo donde la navegación era cosa corriente. Además, en 1848 , la firma del Tratado de Guadalupe, hecho por el cual México perdió un territorio, entre los Ríos Nueces y Bravo, equivalente a unas 2,350 leguas cuadradas (unos 40,000 kilómetros cuadrados), y la fundación del actual Nuevo Laredo, con numerosos vecinos del antigüo San Agustín de Laredo que, para entonces, pasó a formar parte de Texas. ${ }^{11}$ Para 1848, he estimado en unos 2,000 habitantes, entre euro e indomestizos, la población de la municipalidad de Reynosa; de este total, la gran mayoría esta compuesta de rancheros analfabetas, viviendo en chozas de paja, sin escuelas ni servicios públicos; en esta época, los indios no son tan mencionados: parecieran haber sido totalmente exterminados, asimilados a la población local, o huído a la montañas del sur. El semidesierto comenzaba a ser conquistado por pastores de ganado menor.

Las Leyes de Reforma y de Comercio Libre, junto con la Guerra de Secesión en los Estados Unidos, se traducen en el noreste o distrito norte de Tamaulipas en un crecimiento económico muy significativo que fue la "primera época del algodón". Matamoros es la municipalidad que recibe los más importantes beneficios, aunque las ganancias de Reynosa no debieron ser despreciables. El bloqueo de los puertos norteamericanos hizo que las cosechas de algodón en Texas y Luisiana al exterior vía Matamoros. Por otro lado, mayores extensiones cultivadas de tierra, tal propiedad individual, marcaron las primeras exportaciones a Europa de la borra blanca desde el noreste y, desde luego, el mayor número de empleos a jornaleros y pizcadores. Así mismo, el comercio se vió ampliamente favorecido con el tráfico de pieles a Nueva York y la exportación de ganado en pie hacia regiones sureñas de los Estados Unidos. Las modificaciones al arancel aduanal y la habilitación de Reynosa como puerto y aduana fronteriza fueron sucesos que procuraron mayores incrementos económicos a ciertos sectores de población. Hacia 1870 , ya había en el noreste casas de adobe

$\overline{10}$ Vigness, David M. La República del Rio Bravo. En Estudios de Historia del Noroeste. Sociedad Nuevoleonesa. Monterrey. 1972, pp. 183-190.

11 Op. cit. Anónimo. 
y muchas de piedra, 8 haciendas y 498 ranchos en los cuales se hallan repartidos 1,740 sitios de ganado mayor; Reynosa, la municipalidad, cuenta con 3,724 habitantes, mientras las otras del Noreste resultan mayores, como Matamoros con cerca de $15,000 .^{12}$

Durante el Porfiriato (1877-1910), hubo un crecimiento generalizado en el área del distrito norte de Tamaulipas, registrando Reynosa su parte correspondiente. Así, extensas zonas de terrenos baldíos y tierras nacionales fueron vendidas a ciudadanos nacionales e inversionistas extranjeros, como otro programa de política que fortaleciera la colonización y la industria de México. Reynosa, sin embargo, no perdió su naturaleza rural ni su economía raquítica, en comparación con Nuevo Laredo y Matamoros que eran los centros semiurbanos con los mayores riesgos.

En este sentido, desde la década de 1880 , Nuevo Laredo constituía la segunda aduana en la república, por sus derechos fiscales, después de Veracruz; y entre 1890 y 1891 se importaron por Nuevo Laredo cerca de siete millones de pesos, tal valor por diversos géneros, y se exportaron por unos tres millones y medio de pesos, valor de metales preciosos, minerales y otros artículos. Para entonces, ya corría de Laredo el Ferrocarril a Monterrey y la ciudad de México y se tendían las vías de otro hacia Matamoros, pasando por Reynosa.

Esta municipalidad se asienta con más de 6,200 habitantes, ${ }^{13}$ con unos 2,400 en la villa-cabecera, 4,056 cabezas de ganado vacuno, 4270 de caballar, unos cientos de mular y asnal y 11,580 de lanar y cabrío. Todo ello representaba un $10 \%$ de la ganadería en el distrito norte de Tamaulipas, así como en población. En Reynosa, numerosos hatos ganaderos son consignados; quizá habrían unos cien ranchos, cuya comunicación y tránsito se hacían muy dificultosos cuando la época de lluvias pues las carreteras se atascaban en lodazales. Por lo que se refiere a cultivos, el algodón había aumentado, mientras el maíz, el frijol, el garbanzo y algunas legumbres y frutales producían, probablemente, suficiente para el consumo local. A todas luces, la región era ya ganadera, de tipo extensivo, y había talleres donde se preparaban vaquetas, pergaminos para fustas, gamuzas y muchas pieles curtidas, además de estar muy adelantadas la talabartería, la carpintería, la herrería y, en algunas villas, los tejidos de lana, algodón y jarcia. Por otra parte, en 1890, había tan sólo un hospital municipal en Matamoros,

12 Prieto, Alejandro. Historia, geografía y estadística del estado de Tamaulipas. Tipografía Escalerillas 13, México. 1873, pp. 330-1, 335-8 y 341.

13 Si la cifra es correcta, el incremento mayor a un 66\% en el lapso de 20 años (recuérdese, 3,724 habitantes en 1870) implica, quizá, significativos cohortes migratorios provenientes, lo más seguro, de Nuevo León y de San Luis Potosí, como se verá más adelante. 
y seis escuelas primarias públicas (una para niñas) con unos cien alumnos, en Reynosa, municipalidad que tenía un presupuesto de ingresos y egresos anuales, oscilante entre mil cien y mil setecientos pesos. En todo el distrito norte habían 22 hectáreas de riego y 2,857 de temporal bajo cultivo. ${ }^{14}$

Al analizar los datos y cifras anteriores, es acertado pensar que al inicio de siglo ya existiera una hacienda, Colambres, y una población económicamente activa compuesta de unos 2,200 individuos, más de la mitad de los cuales se dedicaba a la agricultura, en calidad de rancheros y/o peones, distribuyéndose los demás en las ramas de comercio, de servicio, en los talleres, en la construcción, en los transportes, en el gobierno y entre los empresarios regularmente ricos y quienes trabajan por su cuenta (véase cuadro 1). Asimismo, es dable aseverar que la balanza comercial continuaría favoreciendo a los Estados Unidos, mientras la zona libre incrementaría las ganancias de los intermediarios y de los negociantes locales, incluyendo a los exportadores de ganado en pié y artículos manufacturados en los talleres. Por otro lado, los inversionistas extranjeros y el ferrocarril, controladores principales de la distribución de productos, habrían de obtener pingües utilidades, al igual que los contrabandistas quienes operaban en ambas zonas fronterizas. En consecuencia, mal económicamente la hacienda pública y los pequeños campesinos, productores de maíz, y los cientos de jornaleros.

En otras palabras y aunque no disponemos ahora de cifras probatorias, aceptamos que ya estaba presente la condición de frontera, correspondiente a Reynosa, en condiciones de bastante dependencia comercial a los Estados Unidos. Mientras, por otro lado, hechos internos, como el desarrollo de los campos de algodón y los hatos ganaderos de propiedad particular, fortalecían la estructura muy diferenciada en la tenencia y en la ubicación de los predios agrícolas (ranchos y haciendas); así como el uso y aprovechamiento de la tierra y la gran asimetría en la distribución de las ganancias. El crecimiento y el desarrollo hegemónico de la ciudad de Monterrey debió pesar en los efectos internos que tuvieron lugar en la Villa de Reynosa, aunque carecemos de datos y cifras concretos para comprobarlo ahora.

En 1910, el Anuario estadistico del estado de Tamaulipas consigna la municipalidad de Reynosa con unos 9,000 habitantes, la mitad en la villa villa-cabecera; dos haciendas, Colombres y sus seis ranchos anexos, propiedad de la Compañía Santeña, y Santa Elena, con cuatro ranchos anexos, propiedad de José María Reséndiz y 159 ranchos. Asienta, asimismo, la existencia de unos 1,300 jornaleros (mil hombres y 300 mujeres) que ganaban un peso diario ellos y veinticinco centavos ellas; una producción de 300,000 kilos de

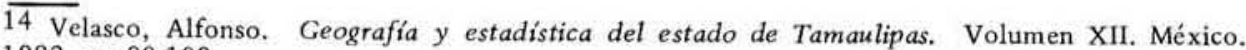
1982, pp. $90-109$. 
CUADRO I. Cifras estimadas y ajustes censales correspondientes a Reynosa : 1650-1930. Fuentes asentadas en el texto.

\begin{tabular}{|c|c|c|c|c|c|c|c|c|c|c|c|}
\hline & 1650 & 1700 & 1750 & 1803 & 1848 & 1870 & 1890 & 1900 & 1910 & 1921 & 1930 \\
\hline Población total & 6,000 & $4,260^{1}$ & 2,350 & $450^{1}$ & $2,000^{2}$ & $3,724^{4}$ & 6,202 & 7,050 & 9,000 & 10,000 & 12,346 \\
\hline Población cabecera & - & $260^{2}$ & $500^{2}$ & $650^{2}$ & $1,000^{2}$ & $2,010^{2}$ & $2,400^{2}$ & 3,000 & 4,400 & 4,600 & 4,800 \\
\hline Población rural & $6,000^{1}$ & $4,000^{1}$ & $2,000^{1}$ & $1,800^{1}$ & $1,000^{2}$ & $1,714^{2}$ & $3,802^{2}$ & 4,050 & 4,600 & 5,400 & 7,546 \\
\hline Migrantes internos & - & 260 & 300 & 320 & 400 & $600^{4}$ & $1,500^{4}$ & 2,000 & 2,500 & $3,000^{8}$ & $3,500^{8}$ \\
\hline Población econ. act. & $2,000^{1}$ & $1,300^{1}$ & 700 & 710 & 700 & 1,600 & 2,000 & 2,200 & 2,600 & 3,000 & 3,800 \\
\hline Agricultura & $2,000^{8}$ & $1,280^{3}$ & 614 & 593 & 608 & 1,330 & 1,400 & 1,500 & 1,800 & 2,200 & 2,900 \\
\hline (Jornaleros) 5 & - & (20) & $(40)$ & $(45)$ & (60) & $(300)$ & $(600)$ & $(1,000)$ & $(1,300)$ & $(1,500)$ & $(1,800)$ \\
\hline Talleres ind. & - & 10 & 30 & 36 & 35 & 70 & 125 & 130 & 135 & 120 & 100 \\
\hline Construcción & - & 2 & 10 & 12 & 8 & 20 & 70 & 100 & 110 & 60 & 100 \\
\hline \multicolumn{12}{|l|}{ Comunicación y } \\
\hline transportes & - & 3 & 10 & 12 & 8 & 20 & 60 & 80 & 90 & 55 & 65 \\
\hline Comercio & - & 2 & 16 & 23 & 20 & 80 & 155 & 180 & 210 & 250 & 300 \\
\hline Servicios & - & 1 & 10 & 12 & 10 & $60^{6}$ & 145 & 160 & 190 & 230 & 255 \\
\hline Gobierno & - & 2 & 10 & 12 & 11 & $20^{7}$ & 45 & 50 & 65 & 85 & 113 \\
\hline
\end{tabular}

${ }_{1}^{1}$ Refiérese, principalmente, a población indígena casi nómada y sin control por parte de las misiones o el gobierno secular.

2 Se trata de criollos y mestizos, quienes fundaron Reynosa, tal migrantes; de otros posteriores migrantes y de los descendientes de ambos.

3 En esta fecha la población india no era agricultora, sino cazadora y recolectora.

${ }^{4}$ Esta cifra ya acusa la gran importancia de los migrantes intemos, procedentes principalmente de San Luis Potosí, Nuevo León y Coahuila.

$5 \mathrm{En}$ las décadas del presente siglo incluían una que otra pequeña industria y las actividades extractivas.

6 De esta década y en adel ante incluirían a los profesionistas y otras ocupaciones liberales.

7 De esta década y en adelante incluirían a los profesores de escuelas y quienes trabajan en la administración pública.

8 Para estas décadas ya los migrantes de Nuevo León sobrepasan a los de San Luis Potosí, y creemos que ya hay un buen número de Guanajuato. 
algodón con valor de $\$ 24,000$, ciēn mil kilos de caña de azúcar, 50 hectolitros de frijol y dos mil hectolitros de maíz con valor de $\$ 7,000$. En cuanto al ganado, son consignadas más de 12,000 cabezas de vacuno, tres mil y pico de caballar y más de 26,000 de caprino. Por otra parte, la institución primaria aparece ofrecida por cinco escuelas oficiales y dos particulares; de las primeras, dos en la Cabecera y tres en el área rural, siendo dos de varones, dos de niños y una mixta, con un total de 377 alumnos, cuya asistencia media era de 178 , presentando examen 170 , aprobaron 152 y concluyeron 18; respecto a las escuelas particulares, una era para 35 varones y la otra para niñas (32), con asistencia media de 25-19, respectivamente, examinando tan sólo a 11 varones de los cuales aprobaron y concluyeron 9. Los sueldos anuales devengados por los 7 maestros de las escuelas oficiales alcanzaron $\$ 2,940.15$

Ahora, también, podemos estimar en unas 2,600 personas la población económicamente activa y, quizá, más de la mitad ocupada en la agricultura, principalmente tal 500 rancheros, con sus parcelas chicas y regulares en tamaño, y 1,300 como jornaleros. Aunque no tenemos datos y cifras respecto a las estructuras y condiciones sanitarias de las viviendas, suponemos que los muros de adobe y ladrillo serían tan comunes como los techos de teja o paja, sin agua potable ni drenaje ni luz eléctrica, mientras se carecería, igualmente, de excusados y fosas sépticas. El poblado cabecera o Villa de Reynosa, de seguro, crecía sin ningún plan y las casas eran levantadas donde conviniera o donde se pudiera. Por lo demás, la dependencia e interrelación con los Estados Unidos continuaba en base a la conducta empresaria y administrativa expresada por algunos sectores de la población de Reynosa, que parecen estar constituyendo los cimientos de una clase media.

El movimiento armado popular, que inicialmente luchó por el derrocamiento del dictador Díaz, se convirtió en demandas por tierra. En el noreste, según la tradición oral, no hubo luchas ni demandas. Uno que otro levantamiento y el recuerdo del general Lucio Blanco quien, defendiendo el orden constitucionalista, toma Matamoros, particularmente su aduana, para controlar el comercio exterior y la posibilidad de introducir armas a México, son los sucesos más significativos. No obstante, parece que en 1913, en la hacienda "Los Borregos", propiedad del generl Félix Díaz, en el municipio de Matamoros, reparten el primer ejido en la república. ${ }^{16}$ Aunque no sabemos más de otras cuestiones agrarias correspondientes a Reynosa, las estudiaremos en nuestra actual temporada de trabajo de campo y de consulta documental.

$\overline{15}$ Gobierno del Estado. Anuario estadístico del estado de Tamaulipas. Tomo II, Año 1909, Número 9. Formado por la Dirección General Técnica. Establecimiento Tipográfico del Gobierno. Victoria. 1910.

16 Op. cit. Anónimo. 
Entre 1920 y 1930 , según las tradiciones recabadas, los "hombres de paja" y los prestamistas ejercían el control sobre la agricultura, principalmente, algodón, el comercio, los talleres y las pequeñas industrias. La malvácea, que en 1905 había producido unas 32,000 pacas de 230 kilos, en todo el distrito norte, en 1925, con ayuda de riego produjo tan sólo 14,000 pacas, cifra que resulta el promedio para la década. ${ }^{17}$ Reynosa contribuyó con unas 1,800 pacas tal promedio anual. ${ }^{18}$ Por lo que se refiere al proceso demográfico, éste continuó lento. Las cifras conocidas consignan unos diez mil para el municipio en 1921 y 12,300 para 1930, residiendo en la cabecera 4,600 y 4,800 respectivamente, mientras el área rural se había incrementado en un porcentaje mayor.

En 1930 existía una hacienda, "Río Bravo", dos congregaciones, "Garza" y "Reynosa Díaz", una ranchería, "Laguna Seca”, mismas que todavía existen, y 204 ranchos. ${ }^{19}$

Dado el número de ranchos y la población asentada en algunos de ellos, es de estimar su gran dispersión y un total promedio en cada uno de 35 habitanes. Así mismo, estimamos una población económicamente activa de unos 3,800 individuos, pero $75 \%$ ocupada en las actividades primarias. La villa había sido declarada ciudad en 1926, incrementó muchos tipos de transacciones comerciales con el lado norteamericano y sustituyó el servicio de lanchones que, desde antaño, comunicaba con el poblado de Hidalgo en el condado del mismo nombre en Texas.

Ante la necesidad de comprobar, aunque sea en parte, el qué y el cómo de la migración y los desarrollos asimétricos en Reynosa, como caso ilustrativo de la frontera norte, sentimos que un marco de referencia teórico podría ser intentado. Así, nuestro propio concepto de asimetría (carencia de proporción adecuada entre las partes de un todo entre sí y como el todo mismo) ofrece esta oportunidad. Y si nuestras variables son migración y desarrollo, veamos cómo se han manifestado y comportado hasta ahora.

Desde la presencia de los primeros colonos en la región de Reynosa, hacia 1749, primer organizado movimiento de población, los asentamientos, las actividades y los modos de vida de los residentes fueron diferentes. Quienes

\footnotetext{
$\overline{17}$ De seguro, la intranquilidad provocada por las revueltas armadas detuvieron, $\mathrm{y}$ aún disminuyeron, la producción de algodón y su comercio; además, el proceso demográfico se vió frenado entre 1910 y 1921 . (Véase cuadro 1 ).
}

18 Secretaría de Agricultura y Fomento. Estadísticas sobre algodón. Decenio 1925-34. Dirección de Economía Rural. Departamento de Estadística Agrícola. México. 1935.

19 Torrea, Juan Manuel. Diccionario Histórico Geográfico de la República Mexicana. Estado de Tamaulipas. Sociedad Mexicana de Geografía y Estadística. México. pp. 40 y 404-07. 1940. 
se dedicaron a la ganadería menor, a la agricultura de maíz, a la producción y curtido de pieles, a la extracción de sal, al comercio, al ramo de servicios, etc., crearon un diversificado sistema de relaciones sociales cuya estructura y producción económica acusó diferencias. Los productos del trabajo y del capital tuvieron diferente precio y valor; de acuerdo a las demandas por satisfacer.

El crecimiento de la población y el desarrollo productivo y de consumo, aunque lentos, durante los primeros cien años, conservaron y fortalecieron la asimetría entre las partes o componentes del sistema social. La "primera época del algodón", entre 1850-1870, debió acelerar los ritmos y dirección de algunos cambios estructurales, muy significativos. La municipalidad de Reynosa dobla su población (de unos 2,000 a 3,724) y en cientos de foráneos, dado que la producción de algodón, con sus procesos complementarios y suplentarios de distribución, demanda una fuerza de trabajo asalariado (peones, jornaleros y empleados menores). Esta forma de actividad creó riqueza para algunos de los sectores de la población, particularmente quienes controlaban los medios de producción.

Al mismo tiempo, el trabajo asalariado y la producción agrícola comercial fortalecían una red de mercado respecto a los artículos necesarios de consumo. Las relaciones de producción y comerciales con Europa, al principio, y después con los Estados Unidos de América, determinó una situación de dependencia y fortaleció la condición socioeconómica de Reynosa tal unidad-frontera. La situación de dependencia y la condición de frontera singularizó a Reynosa y selló su destino.

En esa época, los atributos y características socio-económicas y culturales de Reynosa propiciaron y fundamentaron un tipo asimétrico de crecimiento, de desarrollo y de recepción de población foránea. Factores externos (Guerra de Secesión en los Estados Unidos de América, que facilitó la exportación de algodón) y factores internos (producción de la propia borra blanca; la posibilidad de adquirir en propiedad individual más tierras para explotación; y el contar con fuerza de trabajo asalariada) resultaron decisivos; además, ambos hechos económicos (comercio exterior y engrandecimiento de las áreas de producción agropecuaria) fueron elementos constituyentes de la política liberalista implementada para entonces por el gobierno mexicano.

Hipótesis: crecimiento económico basado en comercio exterior y sostenido por peonaje barato, de riqueza a empresarios y pobreza a jornaleros.

En otras palabras, el inicial comercio exterior del algodón y su cultivo y exportación posterior en Reynosa demandó tierras, pizcadores y otras 
formas de trabajo asalariado, al mismo tiempo que incrementó las áreas y los excedentes de producción agrícola y ganadera de propiedad individual. La emergencia de una red comercial para artículos de abasto y consumo fue un hecho lógico y necesario, así como el surgimiento de otros tipos de actividades salariales compuestos por el grupo de obreros y por el ramo de empleados en el gobierno y en los rubros de distribución y servicios, aparte de los comerciantes y artesanos tal trabajadores por su cuenta. Las demandas de la producción y de la distribución de la ganadería y de algodón resultaron sí crecientes, pero aleatorios y sujetas a los requerimientos del mercado exterior. Sin embargo, la adquisición de artículos y bienes de consumo era un hecho constante. La riqueza obtenida por los empresarios agrícola-ganaderos, fruto de su ganancia en el sistema capitalista, podría variar y aún disminuir, más la satisfacción de las necesidades de la población campesina, jornalera o empleada no resultaba aleatoria. El concepto de asimetría adquirió vigencia mayoritaria, tanto en los ingresos como en los egresos.

En efecto, el proceso de crecimiento económico y migratorio de Reynosa parece acelerarse entre 1886 y 1910 . El Porfiriato busca más comercio exterior y se propone industrializar el país. Más inversiones de capital extranjero y más concesiones y ventas de tierra son otorgadas a empresarios nacionales y extranjeros $\mathrm{y}$, posiblemente, pues no disponemos de datos y cifras concretas, el número de propietarios disminuyó, pero sus cultivos y extensiones de tierra fueron mayores, así como más elevado el de jornalero -estimamos unos 60 en 1850; 120 en $1860 ; 300$ en $1870 ; 600$ en 1890 y 1,300 en 1910- y el de otros asalariados. En relación con lo anterior, el número de cabezas de ganado mayor aumentó de unas 4,000 en 1890 a unas 12,000 en 1910 y el ganado menor de 11,580 a 26,000. ¿A más peonaje, mayor explotación agropecuaria y más crecimiento desigual?

También, la producción de algodón fue creciente. De los pocos cientos de hectáreas y pacas cosechadas en el período $1850-1870$ pasó a miles entre 1886 y 1910 . No obstante, lapsos de recesión en esos 15 años debieron mostrar los peligros del monocultivo, de la zona libre. de la libertad de comercio, de la inversión en capital foráneo, de la dependencia al exterior y de la falta de planeación y de política económica para beneficio social; sin embargo, el sistema capitalista imperante, tanto en Europa, Estados Unidos de Norteamérica y México, impuso sus reglas y continuó el desarrollo asimétrico. Las ganancias correspondieron a partes desiguales y la gran mayoría de la población no recibió los beneficios justos y equilibrados. La escasa educación formal y la insalubridad fueron notorias.

Por otro lado, al nivel de migración interna hacia Tamaulipas, nuestro estimado total de unos 120,000 habitantes en 1870 supone un $10 \%$ de naci- 
dos fuera de la entidad. Esta cifra tiene relación con el $15.5 \%(32,000)$ de migrantes que existían en 1895 , el $13.8 \%(30,000)$ en 1900 y el 13.1 $(29,000)$ en 1910 , cuando Tamaulipas tenía un cuarto de millón de habitantes. De esos cohortes y flujos migratorios, por estar seguros de que el distrito norte fue el que creció más, aceptamos que gente de San Luis Potosí $(17,000,14,000$ y 12,000) y de Nuevo León $(7,300,8,600$ y 9,600) constituyeron los mayores contingentes, en números redondos, en Reynosa, Laredo y Matamoros, de acuerdo a los porcentajes expresados en los censos nacionales de esas fechas. ${ }^{20}$ Resulta significativo asentar que hasta 1910, Tamaulipas había recibido 9,570 neoloneses y enviado a Nuevo León, 5,799 nativos. 21

Durante los veinte años siguientes (1911-1930), las vicisitudes revolucionarias tuvieron efectos en la disminución de algodón, por el abandono de algunos campos de cultivo; en los 1920 s. Recupera un tanto su ritmo productivo, pero las ganancias diferenciales por 1,800 pacas, en promedio anual, obtenidas en unas 2,400 hectáreas, mantienen.la semejante asimetría en el proceso de desarrollo socio-económico y en las numerosas ocupaciones de asalariados -estimamos- unos 1,500 jornaleros en 1921 y 1,800 en 1930 , cuando más del $70 \%$ de la fuerza de trabajo $(2,200$ y 2,900$)$, en un total estimado de 3,000 y 3,800 en la población económicamente activa), respectivamente- se dedicaba a la agricultura y la ganadería.

En relación con las cifras anteriores, la población de Reynosa se incrementó lentamente y, casi seguro, sin importantes flujos migratorios. De unos 9,000 residentes en la municipalidad hacia 1910 (50\% en la cabecera y $50 \%$ en el área rural), se estima en unos 10,000 la población para 1921 y el Censo Nacional de 1930 registra unos 12,300 (4,800 en la cabecera y 7,500 en el área rural). Fueron éstas, décadas de escaso desarrollo y más bién, de "nueva consolidación de la estructura económica anterior" con semejantes índices de carencia en escuelas, industrias y salubridad. Las mayores conmociones habrían de venir en las décadas siguientes. Hasta aquí, entonces, nuestro intento de ofrecer un esbozo del marco de referencia teórico correspondiente al desarrollo económico y a los movimientos de migración interna, en Reynosa, ambos asimétricos, según las situaciones de dependencia y las condiciones de frontera, vistas desde una perspectiva local, regional y nacional.

Sin embargo, la migración interna que ocurrió en Reynosa hasta 1930, aunque sí produjo cambios, particularmente en el fortalecimiento de un sis-

\footnotetext{
20 Secretaría de Economía. Estadísticas Sociales del Porfiriato, 1977-1910. Recopiladas por Moisés González Navarro. Dirección General de Estadística. México. 1956.

21 González Navarro, M. Población y Sociedad en México (1900-1970). Tomo I. Facultad de Ciencias Políticas y Sociales. Serie Estudios No. 42. UNAM. México.
} 
tema de relaciones basado en la dependencia interna, hacia los pequeños o grandes empresarios agrícolas nacionales, y en la dependencia externa, hacia los grandes consorcios de Estados Unidos, no reflejó modificaciones significativas en los niveles de vida.

Así, por ejemplo, los incrementos de población en Reynosa, desde fines del siglo pasado, aumentaron seguramente el número de ranchos. Cifras relativas a Tamaulipas consignan 1,631 en $1900 ; 3,171$ en $1910 ; 2,487$ en 1921 ; y 3,526 en $1930 .^{22}$ Fueron, como sabemos, pequeños núcleos de población, vecinos a la villa y luego ciudad de Reynosa, o creados muy cerca y dentro de los propios campos en cultivo de las explotaciones algodoneras, maiceras y ganaderas.

En relación con lo anterior, creemos que el mayor número de ranchos y el incremento de sus residentes se debió fundamentalmente, a los migrantes internos. Estos, con gran necesidad de trabajo para sobrevivir, laboraron como peones, ya que las necesidades de mano de obra barata vinieron y más en aumento. Desgraciadamente, estos grupos de campesinos carecían de conceptos y visiones económicas, como productos de reflexión o de conocimiento, y no pudieron defender sus legítimos salarios. Sabemos que durante el Siglo XIX el jornal de los peones, en términos generales, no fue mayor de cuatro reales; pero en las primeras décadas del siglo XX ese jornal no había aumentado significativamente y sí, en cambio, los precios del maíz, del frijol y del chile habían subido hasta cuatro tantos. Además, entre las décadas de 1922 a 1931 el valor adquisitivo del peso mexicano había disminuído, así como su equivalencia frente al dólar norteaméricano.

Por otro lado, los índices de analfabetismo para la población de Tamaulipas que, en 1921, representaron el $43 \%-70 \%$ en el país-. en 1930 había disminuído al $31 \%-60 \%$ en el país- y solamente el $50 \%$ de la población en edad escolar, de 6 a 10 años declaró asistir a las escuelas primarias. ${ }^{23}$ Suponemos, desde luego, que los índices de analfabetismo en Reynosa serían mayores y menor el número de asistentes a las escuelas, dados los mayores porcentajes de población rural y la ausencia de políticas escolares para esos habitantes.

Semejantes cifras de carencias y deficiencias podrían ser asentadas en lo relativo a las condiciones deplorables de la vivienda, tanto en la ciudad como en el campo de Reynosa, aunque no disponemos de datos estadísticos para esta época.

22 Secretaría de Economía. Quinto Censo de Población (1930). Resumen General. Dirección General de Estadística. México. 1934.

23 Ibidem. 
En otras palabras, y ahora alteramos nuestras definiciones, sí hubo cierto cambio social y económico, en cuanto se ofreció la seguridad de dependencia y la pobreza al campesino de Reynosa, así como algún significativo crecimiento económico para los empresarios agrícolas. No obstante, no hubo desarrollo socioeconómico, cultural y político, si tal vocablo implica avances paralelos en los diversos aspectos de la vida, con iguales o semejantes oportunidades de mejoramiento para toda la población de Reynosa. Las diferencias y de gran injusticia social. Desde luego, el sistema capitalista había sentado sus reales en Reynosa y las utilidades y ganancias se distribuían sin equidad. Como no hubo uniformación en las estructuras económicas y sociales, aunque se logró mayor integración cultural y política, el crecimiento fue asimétrico y carente de justicia social. Las empresas agrícolas y comerciales, de naturaleza capitalista, buscaron y obtuvieron ganancias económicas, mientras los trabajadores, principalmente aquellos asalariados, no recibieron benéficos significativos en los diversos aspectos y niveles socio-económicos y culturales de su vida. 